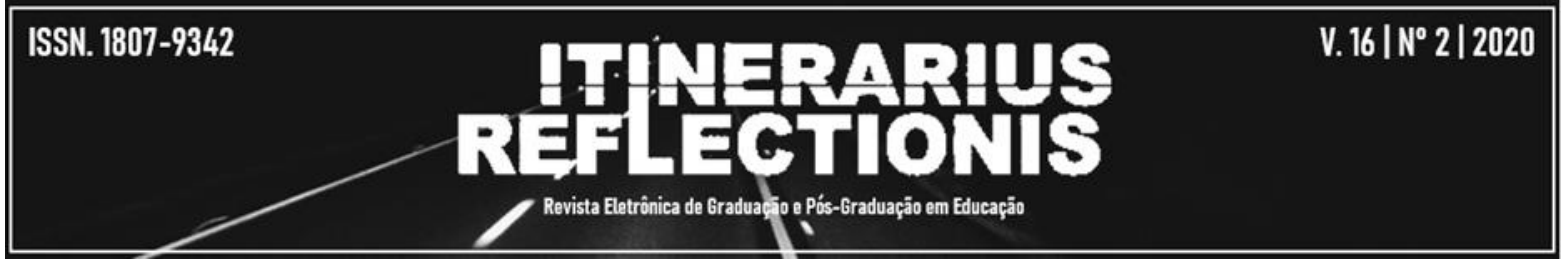

\title{
A interação do conhecimento da matemática e gastronomia para o empoderamento da mulher
}

\author{
Ana Maria Libório de Oliveira ${ }^{1}$ \\ Érika de Oliveira Lima ${ }^{2}$ \\ Caroline soares Santos ${ }^{3}$ \\ Domingos Caitano de Sousa Neto ${ }^{4}$
}

Resumo. O presente artigo tem como objetivo corroborar para o desenvolvimento de projetos que possam estabelecer o crescimento pessoal, profissional $\mathrm{e}$ intelectual de mulheres na contemporaneidade. O projeto teve como finalidade possibilitar o conhecimento da interação da Matemática, com a Gastronomia e o empoderamento de mulheres em situação de vulnerabilidade social, por meio da formação humana e qualificação profissional. Além dessas ações, o projeto possibilitou a reflexão sobre os direitos e deveres constitucionais, a promoção da autoestima, progresso na qualidade de vida, relações familiares e comunitárias e também capacitou na área da Gastronomia. A metodologia direcionou-se com atividades expositivas e práticas, no sentido de intervenção, com explanação da interação da matemática, gastronomia e empoderamento. Apresentou em seus resultados efetivos a aprendizagem da matemática e gastronomia, possibilitando o estabelecimento de relações, assim como, com a intervenção na qualificação profissional e valorização em ser mulher.

Palavras-chave: Empoderamento. Matemática. Gastronomia social.

\section{The mathematics and gastronomy knowledge interaction for empowerment of the woman}

\begin{abstract}
The present article has as goal corroborate for the projects development that can establish the personal growth, professional and intellectual in the woman empowerment contemporaneousness. The project had as purpose enable the Mathematics interaction knowledge, the Gastronomy, the women's empowerment in the contribution of the family income and the professional qualification, women in situation of social vulnerability, by means of a human formation and professional qualification. Beyond of these actions, the project aims reflect about the rights and constitutional duties, promote for self esteem, progress in the life quality, family and of common use relations and, also enable in the Gastronomy area. The methodology it addressed with activities expositive and practices, in the intervention sense, with mathematics interaction explanation, gastronomy and empowerment. It presented in their effective results in the mathematics and gastronomy learning, enabling the understanding and her relations, as well as, the women appropriated with the intervention in the professional qualification and valorization in being woman.
\end{abstract}

\section{Keywords: Empowerment. Mathematics. Social Gastronomy.}

\footnotetext{
${ }^{1}$ Doutoranda em Ciências da Educação, especialidade Educação Matemática pela UMINHO/PT. Mestra em Estudos Amazônicos pela UNAL/CO. Especialista em Docência do Ensino Superior pela UCAM/RJ. Pesquisadora: Matemática, Educação e Sociedade - IFB; NEPECS - IFG; GPEG - UEA e CIEd - UMINHO. Professora de Matemática do Instituto Federal de Brasília - Campus Estrutural. Contato: ana.liborio@ifb.edu.br ${ }^{2}$ Doutoranda em Educação pela UCB. Mestra em Turismo e Meio Ambiente pelo Centro Universitário de Ciências Gerencias e Mestre em Administração. Pesquisadora: Matemática, Educação e Sociedade - IFB e NEPECS - IFG. Professora do Instituto Federal de Brasília - Campus Estrutural. Contato: erika.lima@ifb.edu ${ }^{3}$ Doutora em Sociologia pela UnB. Mestra em Ciência Política pela UnB. Graduação em Ciência Política pela UnB. Pesquisadora: Matemática, Educação e Sociedade - IFB e NEPECS - IFG. Professora de Sociologia do Instituto Federal de Brasília - Campus Estrutural. Contato: caroline.soares@ifb.edu.br

${ }^{4}$ Discente em Licenciatura em Matemática do Instituto Federal de Brasília - Campus Estrutural. Contato: netomat19@gmail.com
} 


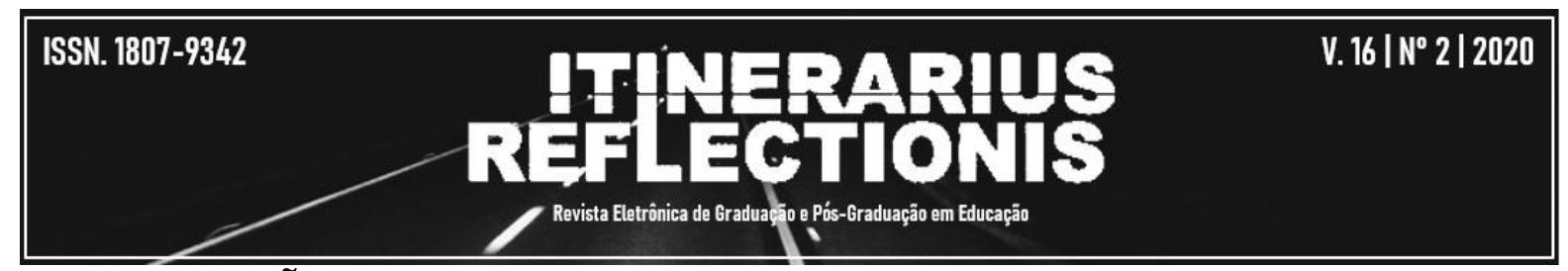

\section{INTRODUÇÃO}

O presente projeto, objeto desta pesquisa, buscou promover a educação matemática por meio da preparação de pratos gastronômicos, desmistificando o conhecimento matemático e aproximando esse conhecimento do cotidiano das mulheres. Segundo os dados do Sistema de Avaliação da Educação Básica - Saeb, em 2016, os índices de desempenho em matemática entre os estudantes da educação básica estagnaram ou, se não, retrocederam, apontando a urgente necessidade de rever os formatos escolares e inovar em metodologias de ensino.

Além disso, somando-se a todo esse dado geral, pesquisas revelam que existem diferenças no desempenho em matemática entre gêneros. De acordo com um estudo divulgado pela Organização para a Cooperação e Desenvolvimento Econômico (OCDE, 2015) com dados recolhidos do Programa Internacional de Avaliação de Alunos (PISA) meninas, incluindo as com desenvolvimento elevado escolar, são mais propícias a ter baixo rendimento em comparação com os meninos, quando solicitadas a pensar em situações matemáticas ou interpretar fenômenos cientificamente.

Assim, o projeto além de popularizar o conhecimento matemático tem o potencial, à medida que se volta prioritariamente ao público feminino, a combater a desigualdade entre gêneros.

A proposta metodológica foi realizar atividades teórica e prática em parceria com IFB - Campus Estrutural no espaço cedido pela Comunidade da Estrutural, denominado Coletivo da Cidade. O público alcançado com o projeto foram vinte duas mulheres, todas em vulnerabilidade social, ademais com participação de dois homens.

O projeto teve como objetivo principal possibilitar o conhecimento da interação da Matemática, a Gastronomia, o empoderamento das mulheres na contribuição da renda familiar, a elevação da escolaridade e qualificação profissional, em situação de vulnerabilidade social, por meio de uma formação humana e qualificação profissional.

Além destas ações, o projeto visou refletir sobre os direitos e deveres constitucionais, promover a autoestima, progresso na qualidade de vida, fortalecer vínculos familiares e comunitários e, também capacitar na área da Gastronomia.

Para alcançar o objetivo geral estabeleceu os seguintes objetivos específicos: apresentar o conhecimento do empoderamento, a Matemática, Gastronomia; aplicar a 


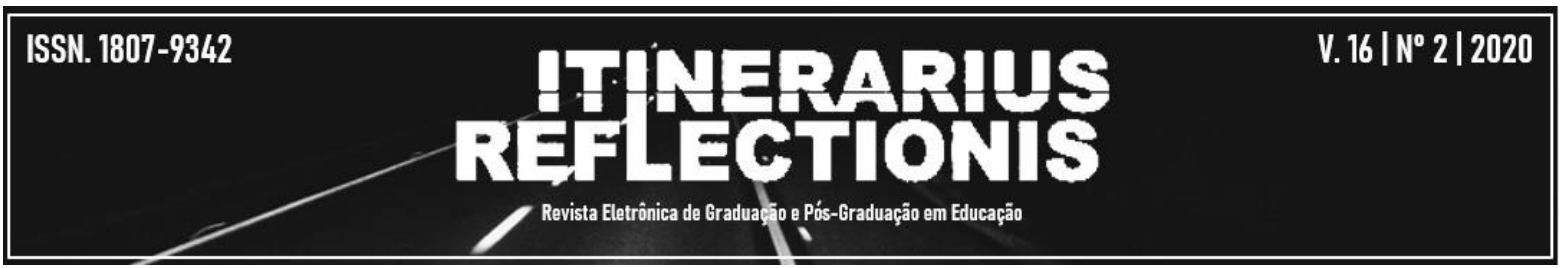

interação dos conhecimentos da Matemática na prática da Gastronomia e capacitar para as práticas profissional, humana e matemática, contextualizando na construção do saber gastronômico

A ação incentivou a inclusão socioprofissional de mulheres da Cidade Estrutural, com a promoção da troca de saberes e com o estímulo ao engajamento escolar. Uma vez que houve a participação de um profissional da gastronomia que desenvolvia um projeto na entidade parceira e com esforço multidisciplinar dos docentes do IFB, representou uma rica oportunidade de troca de saberes comunitários e acadêmicos, além de uma importante estratégia de aproximação da teoria com a prática.

Ao mesmo tempo em que despertou o interesse pelo conhecimento matemático e pelas possibilidades que podem ser conquistadas pelas mulheres no mundo do trabalho, aproximou docentes e estudantes do Campus Estrutural das moradoras da região, sendo assim, um meio profícuo de gerar inovação e pesquisas aplicadas sobre esse contexto específico.

De acordo com a pesquisa por amostragem realizada pela Codeplan, de $4.000 \mathrm{mil}$ domicílios pesquisados, mais de 1.700 apresentam a renda per capita mensal de menos de 1/4 de salário mínimo, e mais de 400 são chefiados por mulheres e idosos em situação de vulnerabilidade, possuindo uma média de 3,8 pessoas por domicílio, ou seja, um quadro crítico de exclusão social.

Portanto, a primeira etapa da ação finalizou com a certificação das envolvidas no projeto e espera-se continuar o projeto em uma segunda etapa, a fim de continuar a formação em gastronomia associada ao conhecimento matemático, conscientes de seus potenciais, desafios e meios de alcançar objetivos, possibilitando ao grupo de docentes e estudantes do IFB de desenvolverem novos projetos que alcancem de forma mais efetiva a realidade da comunidade.

\section{REFLEXÕES TEÓRICAS}

Destaca-se que 2018 foi o ano Biênio da Matemática intitulado "A matemática está em tudo", dessa forma buscou-se com o projeto demonstrar a utilização da matemática para a preparação de pratos. Ressalta-se que o Campus Estrutural tem o Curso de Licenciatura em Matemática, dessa forma, justificando a escolha e execução desta ação. 


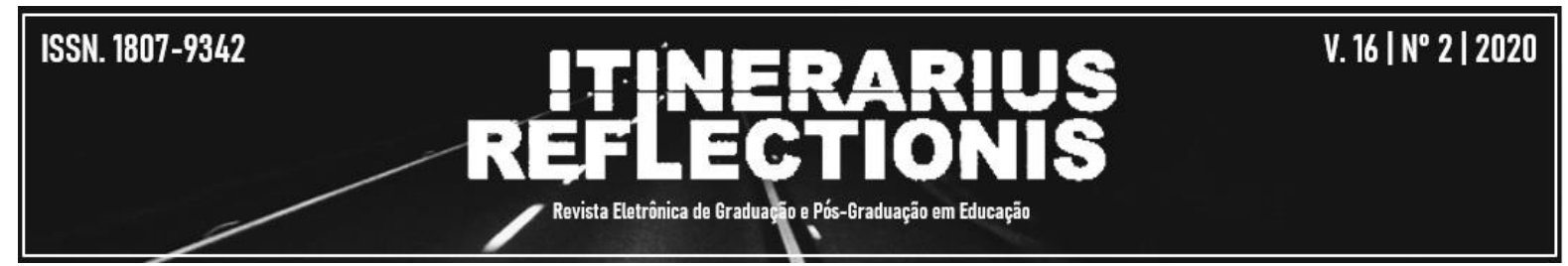

Com base na apresentação do Biênio, assim como, o Curso ofertado no IFB -

Campus Estrutural, em que a união desses fatores agregados à comunidade da Estrutural é percebida que algo deve ser feito para o empoderamento das mulheres pertencentes à comunidade da Estrutural, pois é sabido que "a pobreza e a exclusão social atingem mulheres e homens diferenciadamente de acordo com o sexo porque as mulheres são sobrecarregadas com os trabalhos não remunerados, geralmente ligados às tarefas domésticas e aos cuidados dos filhos" (MELO, 2005, p. 16).

A Matemática desenvolve aspectos financeiros, aspectos econômicos e estimula o raciocínio lógico, assim, pode prover condições profissionais, intelectuais e habilidades que despertem o interesse pessoal, para que as essas mulheres sejam inseridas no mundo do trabalho, promovendo a inclusão social e a cidadania plena.

Com essa ação, estimula o universo feminino na reflexão de sua inserção, responsabilidade, amor e fortalece traços, principalmente no que diz respeito à empatia do valor feminino e seu empoderamento, contribuindo na ação de dar e/ou conceder poder para si próprio ou para outrem, ajudando na construção do domínio de várias situações vivenciadas pela mulher.

Fica evidente que a trajetória de vida dos indivíduos é cheia de histórias que pode deixar claro que alguns padrões socialmente construídos, que parecem que já foram superados, ainda podem estar vigentes. Por exemplo, quando se decide contar a experiência de vida de uma mulher, negra, que após o término de um casamento se sente liberta e impulsionada a voltar aos estudos, em cursar uma faculdade, mesmo com dois filhos e com todas as dificuldades financeiras, percebemos que essa mesma mulher é julgada por querer desempenhar um papel que para muitos ainda não é visto como um espaço no qual a mulher pode ocupar quando se tem dois filhos para criar e sustentar. (GALETTI, 2013, p. 72)

Percebe-se que há uma diversidade muito grande de motivos que levam à mulher das dificuldades encontradas no seu empoderamento e suas realizações pessoais e profissionais.

Para entender o que é se tornar mulher, precisamos compreender a pressão exercida pelo patriarcado sobre as mulheres até os dias de hoje e de como isso pode ser fator decisivo na forma pela qual a maior parte da sociedade enxerga as mulheres e suas relações, principalmente no que diz respeito ao casamento, maternidade e escolarização.

Apesar dos avanços tidos na concepção do que é ser mulher, dos espaços que as mulheres ocupam na sociedade, o papel de esposa, ou melhor, de boa esposa, é quesito fundamental para se distinguir se a mulher tem desempenhado seu papel de forma plena - isso em uma concepção patriarcal, machista, que infelizmente a 


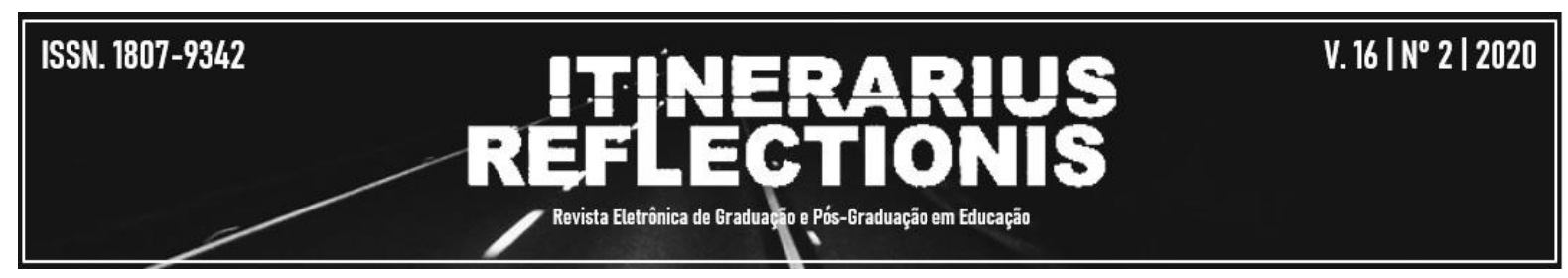

sociedade ainda reproduz e reflete em uma das principais bandeiras de luta das feministas: o fim do patriarcado e do machismo. (GALETTI, 2013, p. 74 - 75)

Ademais, o empoderamento nesta ação, não tem como foco o movimento feminista, enfatizado pela definição de empoderamento das mulheres por Sardenberg (2006), e sim corroborando com as ideias da autora no sentido de que seja o processo da conquista da autonomia e autodeterminação, nesse sentido, viabilizando a intenção maior do empoderamento das mulheres sendo ação do questionamento, assumir maior controle sobre seus corpos e suas vidas (SARDENBERG, 2006, p. 2).

Sobretudo, o que está proposto viabiliza a execução mencionada na Lei de criação dos Institutos $\mathrm{N}^{\mathrm{o}}$ 11.892, de 29 de dezembro 2008, em seu Art. $7^{\circ}$ que ratifica em seus objetivos IV.

Desenvolver atividades de extensão de acordo com os princípios e finalidades da educação profissional e tecnológica, em articulação com o mundo do trabalho e os segmentos sociais, e com ênfase na produção, desenvolvimento e difusão de conhecimentos científicos e tecnológicos. (BRASIL, 2008).

O Coletivo na Cidade é uma entidade localizada na Cidade Estrutural (DF) e atua basicamente com o atendimento de crianças e adolescentes no contraturno escolar oferecendo alternativas artísticas e educativas como meio de transformação social, além de ser importante espaço de convivência comunitária e capacitação profissional para os demais moradores da cidade. A entidade é fruto de uma experiência acumulada, e está aberto à colaboração e participação de todos num grande abraço fraterno e comprometido com a Cidade Estrutural.

A referida ação intervém socialmente, de forma que a ação interage como pressuposto dialógico e transformador com a sociedade, articulando ensino e pesquisa, contribuindo com o processo formativo do educando, envolvendo a comunidade externa.

Assim a ação responde à finalidade de criação dos Institutos que prevê a oferta de educação profissional e tecnológica, em todos os seus níveis e modalidades, formando e qualificando cidadãos com vistas na atuação profissional nos diversos setores da economia, com ênfase no desenvolvimento socioeconômico local, regional e nacional.

Ressalta-se ainda, que o Campus Estrutural iniciou suas atividades no ano de 2012. Seus valores são: ética; educação como bem público e de qualidade; formação crítica, emancipatória e cidadã, respeito à diversidade e à dignidade humana; promoção da inclusão, sustentabilidade econômica e socioambiental. 


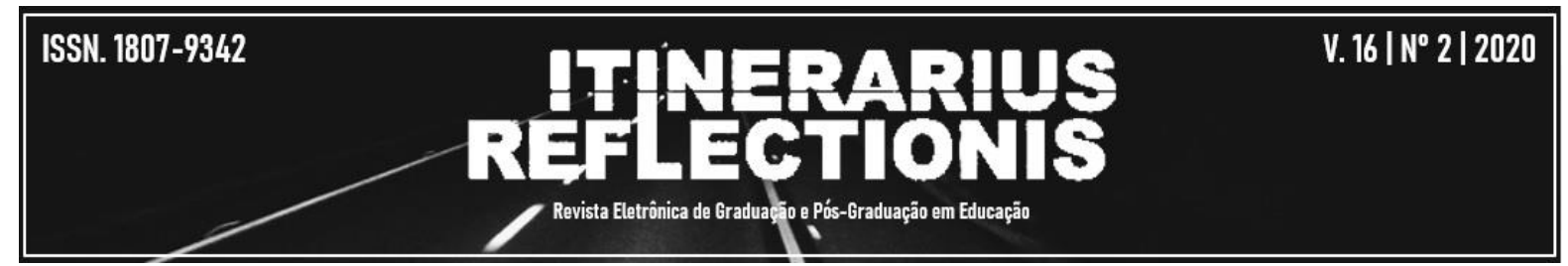

Baseado nesses valores orientativos, dessa forma, o projeto realizado contempla essas premissas, possibilitando acesso às discussões e aprendizagem sobre empoderamento das mulheres, popularização da ciência, educação matemática, porcentagens e unidades de medida e gastronomia social, ampliando a atuação do IFB, possibilitando acesso à educação para grupos sociais em vulnerabilidade social, além de divulgar o Campus junto à Comunidade local.

\section{DIRECIONAMENTOS DAS AÇÕES METODOLÓGICAS}

A proposta metodológica foi desenvolvida por meio de atividades teórica e prática, em formato de intervenção (KAUARK; MANHÃES; MEDEIROS, 2010), as mesmas realizadas em parceria do IFB - Campus Estrutural com a organização da Cidade Estrutural denominado Coletivo da Cidade. No primeiro momento, foram apresentadas palestras sobre empoderamento da mulher, essa por sua vez, ministrada por uma das proponentes da ação.

No segundo momento, foram desenvolvidas atividades teóricas, em que a contribuição da Matemática está sobre a explanação de: Proporções Básicas, Pesos e medidas, Porcentagem e Regra de Três.

Pois, por meio do conhecimento teórico facilita a compreensão, contextualização e aplicação das atividades práticas. Essas atividades foram supervisionadas pela Docente Licenciada em Matemática, que compõe a equipe do projeto, juntamente com o discente bolsista que executou ação na transmissão do conhecimento matemático contextualizado com a gastronomia.

Concomitantemente ao segundo momento, nas aulas práticas, foram realizadas a produção de pratos, através de orientações de um Chef de cozinha, voluntário no projeto, Gustavo H. Valente Egilio, que explanou à gastronomia e as normas para a realização da condução do profissional da área de alimentação.

Por todo o processo da intervenção são realizadas palestras, atividades expositivas e participativas, e atividades práticas de gastronomia.

A Matemática nesta ação apresentou um enfoque também qualitativo, por meio de conceitos, assim como, quantitativos como aproveitamento que está difundido na verificação da participação dos encontros, totalizando no mínimo 75\%, e uma atividade contextualizada 


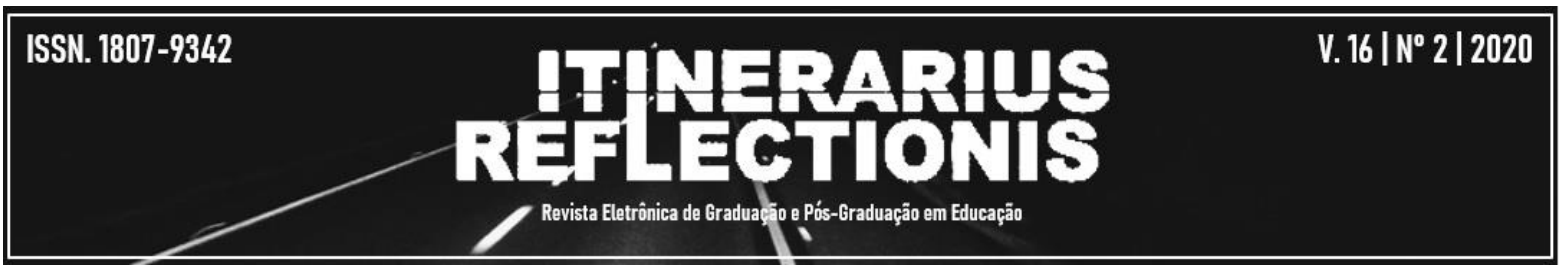

na apresentação prática de transformar uma certa medida de uma gastronomia na produção do valor de venda, custo, lucro e qualidade do produto.

As atividades de gastronomia foram voltadas para o desenvolvimento dos pratos aprendidos, que culminou um jantar de encerramento do projeto no Coletivo da Cidade.

$\mathrm{O}$ acompanhamento dessa primeira etapa foi realizado pela equipe de docentes envolvidos, por meio de participação em todas as etapas do mesmo, buscando minimizar problemas potenciais.

O discente/bolsista contribuiu no auxílio de atividades práticas e teóricas direcionadas à gastronomia, como conversão de medidas, frações, na preparação e explanação dos alimentos e dos valores que os pratos culinários possam ter, pois isso contribuiu para que as mulheres aprendessem a ter lucro de suas práticas gastronômicas e assim, possibilite um crescimento financeiro na renda familiar, produzindo autonomia e independência.

A matemática tem uma importância muito grande dentro da gastronomia, ela nos indica a proporção de cada ingrediente para que se possa chegar ao mesmo resultado e fixação dos conteúdos relacionados às frações (DE PAULA et al, 2017). Serão preparadas algumas receitas envolvendo medidas.

O intuito de relacionar a Matemática e a cozinha faz com que diversas receitas utilizam em seus processos números fracionários, como 1/2 (meia) xícara, 1/3 (um terço) copo americano, entre outras medidas. A adição, a subtração, a multiplicação e a divisão são aplicadas nos processos, assim como, conteúdos como regra de três, proporção, matemática financeira básica, noções de conjunto, operações matemáticas, expressões algébricas e numéricas, dentre outras.

O público-alvo do projeto foram 22 mulheres participantes do Coletivo da Cidade, localizado na Cidade Estrutural-DF, tanto mães como adolescentes. Ademais, houve a participação de dois homens que mesmo tendo conhecimento do direcionamento da ação, quiseram participar.

Para o desenvolvimento contou-se com o envolvimento de 03 docentes, 01 discente do Curso de Licenciatura em Matemática e um voluntário externo pelo Coletivo da cidade, Chef de cozinha.

\section{RESULTADOS E DISCUSSÃO}




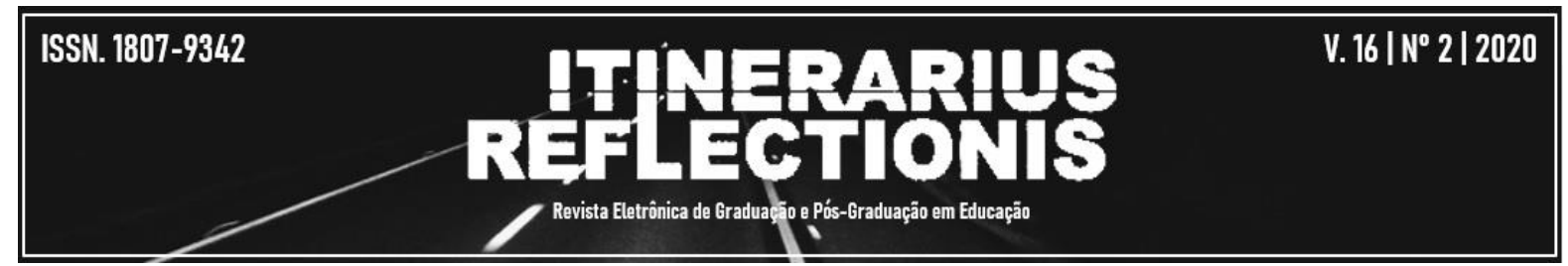

Este projeto teve a pretensão de promover a interação da comunidade acadêmica com a comunidade local, o que foi alcançado com êxito, possibilitando a assimilação da matemática e a gastronomia, uma vez que as diversas receitas utilizam em seus processos números fracionários, além do fortalecimento dos valores e missão do IFB.

A figura 01 mostra as intervenções dos conteúdos da matemática interagindo com o conhecimento gastronômico. Observou-se que esta conexão do conhecimento facilitou a compreensão da realização das atividades. Como exemplo, cita-se uma das atividades: A quantidade de alimento que se fará para um grupo de 10 pessoas, e que em um certo momento esses mesmos alimentos terão que possibilitar um almoço para 80 pessoas.

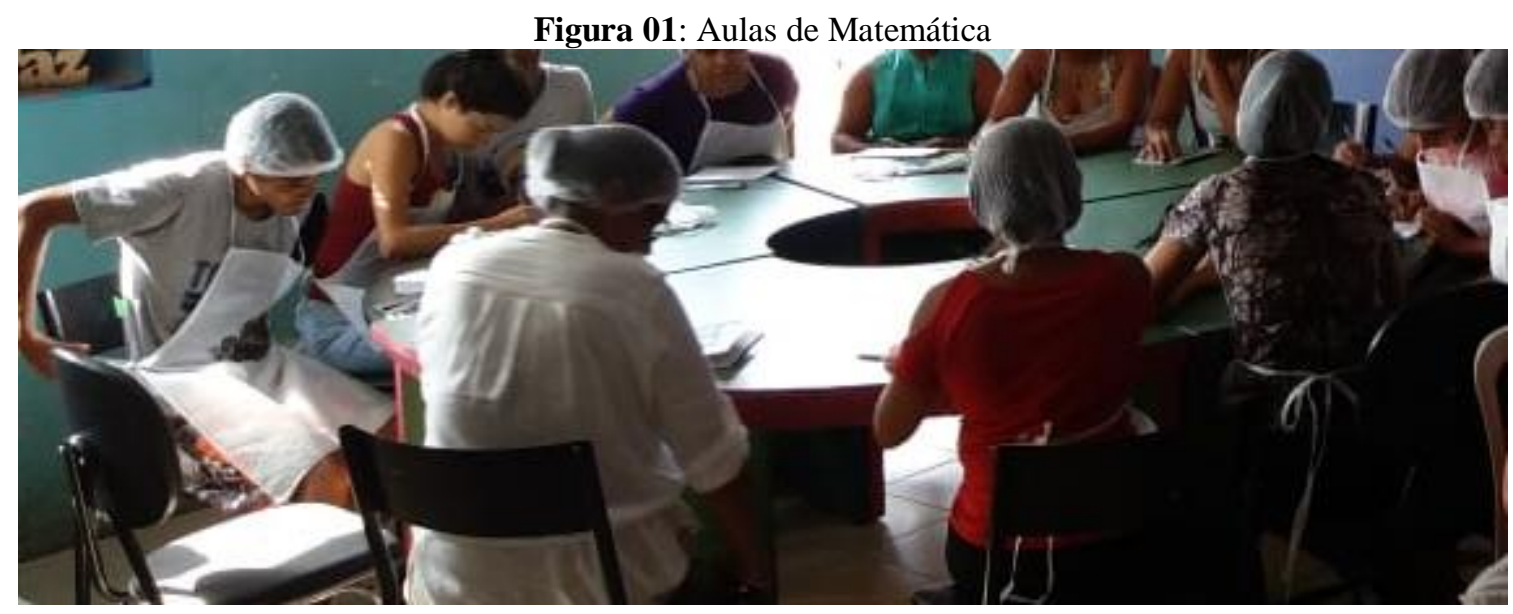

Fonte: Ana Libório (2018)

Foi constatada a aprendizagem significativa (AUSUBEL et al.,1980), tendo em vista que a mesma é uma aprendizagem que deve ter sentido, ou seja, ampla acepção em experiências para quem aprende.

Goulart (2000) cita, com base em estudos de Rogers que distinguiu a aprendizagem significativa como intensa, auto iniciada, conceituada pelo aluno e é conduzida pelo desenvolvimento pessoal.

No primeiro dia da ação foi percebido uma calmaria entre as participantes, pois seria o momento de conhecer o ambiente, a reciprocidade do conhecimento. Ademais, no primeiro dia da intervenção da matemática observou-se o comprometimento das alunas. Como as alunas que participam do projeto de extensão tem baixa escolaridade e algumas delas nunca frequentaram o universo escolar fora utilizado como forma de aprendizado, a visualização. Dessa forma, a metodologia foi de uma aplicação mais visual, pois assim elas 


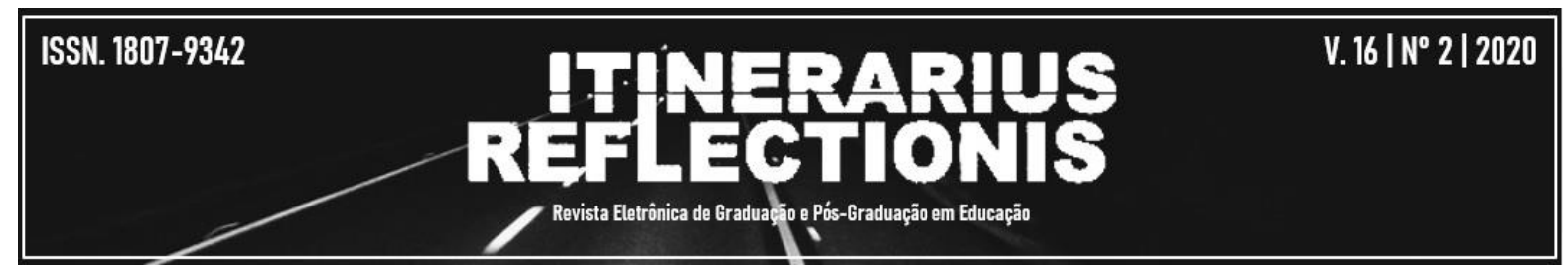

conseguiriam compreender o que está sendo transmitido. Sempre fazendo conexão da Matemática com alimentos.

Uma das dificuldades encontradas foi em ensinar o conteúdo de frações e regra de três, pois elas tinham bastante dificuldades em visualizar e entender o que aquilo representava. Conclui-se que esta deficiência seja em decorrência do tempo que elas passaram fora de sala de aula e de mesmo não ter frequentado por pouco tempo o ambiente escolar, pois no ato da inscrição na ficha para a matrícula foi verificado que parte delas haviam parado de estudar por muitos anos e outras não haviam frequentado o início da educação fundamental completo.

Como pontos positivos pode-se citar a determinação e comprometimento que as mulheres, incluindo os homens participantes, tiveram para com esse projeto de extensão, elas e eles se mostraram bastante motivadas em querer aprender.

$\mathrm{Na}$ figura 2 apresenta a participação das mulheres nas ações da produção dos alimentos, conforme orientações do Chef de cozinha, a mesma mostra a intervenção da dinâmica e dos conceitos gastronômicos.

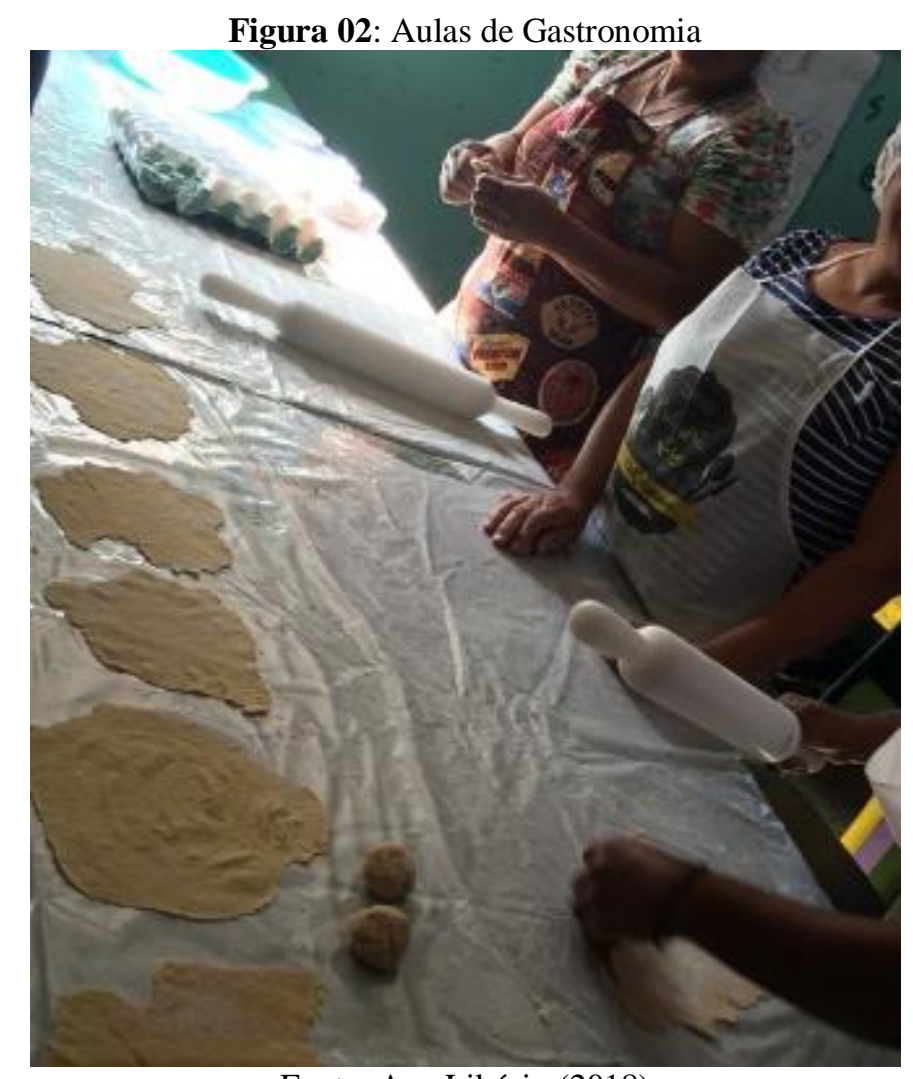

Fonte: Ana Libório (2018) 


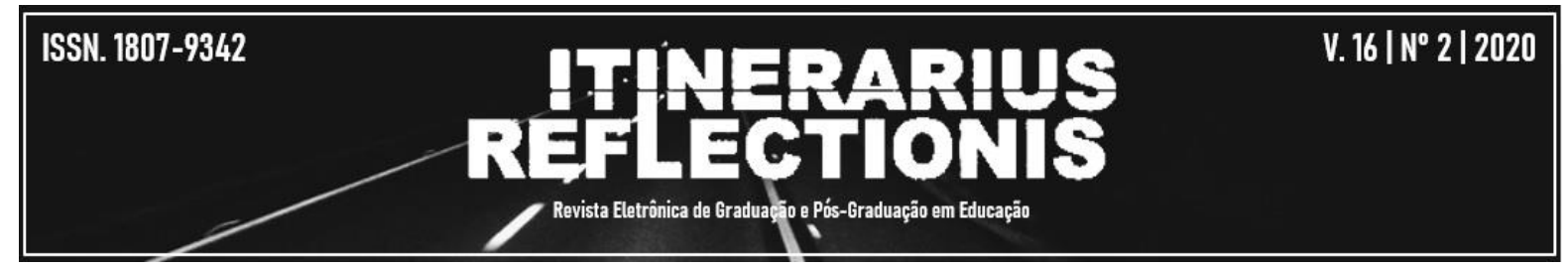

Por meio da figura 2 é visto a produção de massas, observa-se à higiene na execução das atividades e assessoramento do Chef de cozinha, que inclusive fez parte de sua transmissão do conhecimento todos as especificidades da cozinha e a Gastronomia.

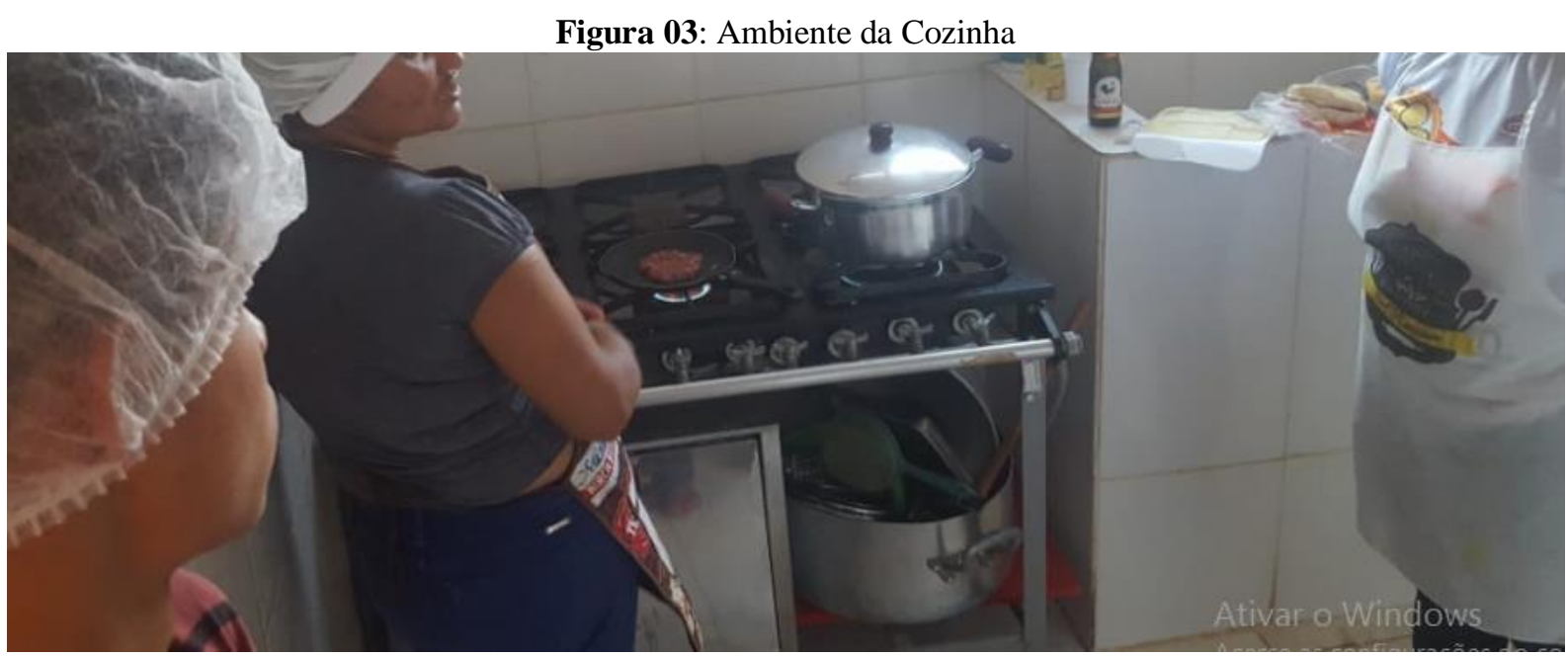

Fonte: Ana Libório (2018)

A figura 03 apresenta o ambiente em que coloca os alimentos na execução no fogão, também com o assessoramento dos cuidados com os alimentos, assim como, os cuidados pessoais e do ambiente.

Apesar, da disponibilidade do acesso à participação dessa ação ser abertas às mulheres, a mesma teve ingresso de homens e que não estava previsto, sobretudo foi admitida o acesso dos dois participantes que atuaram de forma interativa, apresentando muito interesse, com participações ativas nas atividades.

\section{CONSIDERAÇÕES FINAIS}

Esta ação finalizou em novembro de 2018, cujo propósito é a qualificação profissional e o empoderamento da mulher. Interagir a matemática, gastronomia e empoderamento faz-se essencial nos dias atuais.

Dentre essas mulheres, uma delas conseguiu verba pública de projetos para abrir um restaurante de baixo custo, outra conseguiu otimizar os materiais dos seus salgados, viabilizando o aumento de seu lucro e administrando os desperdícios. As demais mulheres e os homens que se inscreveram concluíram com êxito sua formação e conseguiram a certificação. 


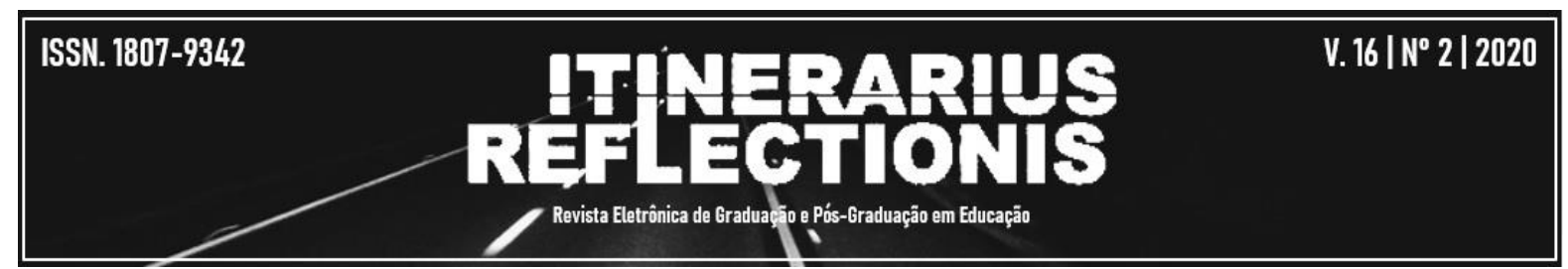

Contudo, não houve acompanhamento, após a formação das concluintes.

Sobretudo, comprovou pelos relatos que a intervenção promoveu uma valorização das mulheres e sua qualificação profissional, elas sentiram-se mais responsáveis por suas vidas e com mais capacidades em transformar uma ação do dia a dia para se conquistar uma renda familiar melhor.

Dessa forma, espera-se que por meio desse projeto as mulheres consigam mudar a realidade econômica, social e política no contexto dessa vulnerabilidade social.

É certo e pode-se afirmar que será um processo lento, mas a promoção já ocorreu, o diferencial já está fazendo parte dessas mulheres e que as reflexões e ações já estão sendo construídas.

\section{AGRADECIMENTOS}

O projeto teve o apoio do voluntário Chef de Cozinha, Gustavo H. Valente Egilio, que atuou no Coletivo da Cidade, assim como, de recursos humanos e financeiros do Instituto Federal de Brasília, do Programa de Concessão de Bolsas de Extensão e Desenvolvimento Institucional no âmbito do Instituto Federal de Brasília.

\section{REFERÊNCIAS}

AUSUBEL, D. P.; NOVAK, J. D.; HANESIAN, H. Psicologia Educacional. Trad. Eva Nick e outros. Rio de Janeiro: Interamericana, 1980.

BRASIL. Lei no 11. 892, de 29 de dezembro de 2008. Institui a Rede Federal de Educação Profissional, Científica e Tecnológica, cria os Institutos Federais de Educação, Ciência e Tecnologia, e dá outras providências. D.O.U. Seção 1, de 30 de dezembro de 2008. Brasília, DF. 2008.

DE PAULA, H. C et al. APRENDENDO A ENSINAR MATEMÁTICA ATRAVÉS DE RECURSOS DIDÁTICOS. Encontro Goiano de Educação Matemática, v. 6, n. 6, p. 419429, 2017.

GALETTI, Carolina Hildebrand. Empoderamento feminino e trajetória de vida: os modelos rígidos do "ser mulher". Revista Vernáculo, n. 31, 2013. 


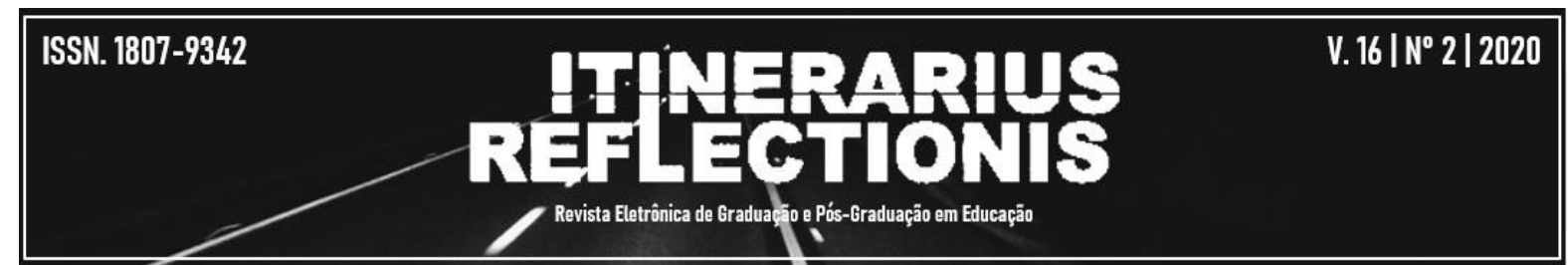

GOULART, I. B. Psicologia da Educação: Fundamentos teóricos. Aplicações à prática pedagógica. $7^{\circ}$ edição. Petrópolis: Ed. Vozes. 2000.

KAUARK, F.; MANHÃES, F. C.; MEDEIROS, C. H. Metodologia da pesquisa: guia prático. Itabuna: Via Litterarum, 2010.

MELO, H. P.; BANDEIRA, L. A Pobreza e as Políticas de Gênero no Brasil. Unidad Mujer y Desarrollo. Projecto Governabilidade Democrática e Igualdade de Gênero. Nações Unidas - CEPAL - Santiago de Chile, junho. 2005.

SARDENBERG, C. M. B. Conceituando "Empoderamento" na perspectiva Feminista. In: I Seminário Internacional: Trilhas do Empoderamento de Mulheres - Projeto TEMPO', NEIM/UFBA, Salvador, Bahia, de 5-10 de junho. 2006. Disponível em < https://repositorio.ufba.br/ri/bitstream/ri/6848/1/Conceituando\%20Empoderamento\%20na\%2 0Perspectiva\%20Feminista.pdf >. Acessado em 09 de novembro de 2017. 